\title{
Deteksi Level Ketinggian Air Dengan Nikelin, Encoder dan Sensor Tekanan Untuk Sistem Peringatan Dini Banjir
}

\author{
Water Levels Detection Using Niceline, Encoder and Pressure Sensor for Flood Early \\ Warning System
}

\author{
Latiful Hayat $^{1 *}$, Dian Nova Kusuma Hardani ${ }^{2}$ \\ ${ }^{1,2}$ Program Studi Teknik Elektro, Fakultas Teknik dan Sains, Universitas Muhammadiyah Purwokerto
}

\begin{tabular}{l}
\hline \hline ARTICLE INFO \\
\hline Article history: \\
DOI: \\
10.30595/pspfs.v1i.132 \\
Submitted: \\
June 28, 2021 \\
Accepted: \\
July 15, 2021 \\
Published: \\
Oct 31, 2021
\end{tabular}

Keywords:

Water level, pressure, encoder, nikelin

\begin{abstract}
Floods and their problems show an increasing indication when rainfall is high. Data from BNPB shows that floods, landslides and tornadoes contributed to the total disasters in Indonesia in a decade. The existence of an early warning flood disaster can help evacuate before a disaster strikes. The system requires a water level detector as the basic data for determining flood predictions. In order to get the water level value, a touch water method can be used using electrodes or without touching the water with the help of pressure sensors, ultrasonic and imaging. Each method has advantages over the other. In this study, the effectivity and accuracy of detecting water levels were investigated using 3 methods: the direct touch of water through nickel wire, buoys with encoder, and pressure sensors. Detection of water levels can be used as a reference to obtain river water level data which is then connected via an IoT or internet connection as a reference for the Early Warning System for the arrival of floods. This study found that changes in water level of less than $30 \mathrm{~cm}$ can utilize buoys and encoders with an accuracy of detecting 5 to 6 counts per $1 \mathrm{~mm}$ increase in water level. Meanwhile, the measurement of less than $30 \mathrm{~cm}$ water level using nickel wire resulted in a non-linear value. The utilization of nickel wire can be used for a height of more than $30 \mathrm{~cm}$ where the change in resistivity has started to be linear. ADC change value is $2.93 \mathrm{mV} / \mathrm{cm}$ using 10 bit ADC at 5 Volt reference voltage. For water level heights of $50 \mathrm{~cm}$ and above, a pressure sensor can use a pressure sensor that can detect changes in pressure of 0.002 in $\mathrm{Hg} / \mathrm{mm}$ or $0.05 \mathrm{mmHg} / \mathrm{mm}$.
\end{abstract}

This work is licensed under a Creative Commons Attribution 4.0 International License.

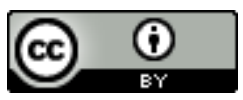

\section{Corresponding Author:}

Latiful Hayat

Program Studi Teknik Elektro, Fakultas Teknik dan Sains, Universitas Muhammadiyah Purwokerto

J1 KH Ahmad Dahlan, PO BOX 202 Purwokerto 53182 Telp. (0281) 636751 ext 130

Email: 1atifulhayat@ump.ac.id

\section{PENDAHULUAN}

Di Indonesia, banjir dan permasalahannya belum dapat diselesaikan secara tuntas, bahkan masalah tersebut justru menunjukkan indikasi yang semakin meningkat, baik-baik dari sisi intensitas, frekuensi maupun persebaran keruangannya. Menurut data Badan Nasional Penanggulangan Bencana (BNPB), bencana yang dipengaruhi faktor cuaca seperti hujan yang tinggi menyebabkan banjir, longsor dan puting beliung menjadi penyumbang terbesar (98\%) dari total bencana yang terjadi selama satu dekade di Indonesia. Dengan kondisi lingkungan yang darurat ekologis, dimana kerusakan lingkungan, degradasi hutan, Daerah Aliran Sungai (DAS) kritis yang meluas membuat bencana banjir dan tanah longsor meluas (BBC News Indonesia, n.d.). Namun, kerugian yang ditimbulkan dari bencana banjir tentu saja dapat dihindari jika masyarakat mendapatkan peringatan akan datangnya bencana banjir. Dengan adanya peringatan, masyarakat dapat melakukan evakuasi sebelum bencana banjir datang. Peringatan tersebut kita dapatkan dengan membuat alat pendeteksi ketinggian air. Melalui alat pendeteksi tersebut dapat digunakan untuk memantau 
pasang surut aliran air. Pasang surut aliran air ini sebenarnya dapat kita amati melalui suhu dan kelembaban lingkungan di sekitar sungai. Sehingga pada saat suhu dan kelembaban tinggi, maka dapat disimpulkan hujan akan turun dan mengakibatkan air pasang (Akhiruddin, 2018).

Sensor yang dapat digunakan untuk mendapatkan nilai ketinggian air adalah kombinasi antara 2 metode, yaitu metode sentuhan air dan tanpa sentuh air. Metode tanpa sentuh dapat menggunakan sensor ultrasonic (Satria et al., 2017). Sensor ultrasonic merupakan salah satu sensor yang dimanfaatkan untuk pendeteksi ketinggian air. Penggunaan metode ini membutuhkan ruang untuk menampung air yang cukup besar dan membutuhkan penampung (Arief, 2011). Pelampung dapat dihindari apabila pengukuran menggunakan metode sentuh air menggunakan sensor tekanan (Ameen et al., 2016). Penerapan sensor tekanan dilakukan di aliran air yang tenang dan menjadi masalah jika terdapat adanya endapan lumpur yang mengakibatkan massa jenis air berubah. Metode pengukuran yang menggunakan sentuhan dengan air adalah menggunakan elektroda kapasitif maupun resistif (Chetpattananondh et al., 2014). Sedangkan pengukuran ketinggian air dapat juga melalui pengolahan citra topology dari angkasa dengan akurasi yang lebih rendah dibandingkan metode sentuh (Raji \& Adedoyin, 2019).

Penelitian ini, mencari efektifitas dan keakuratan dalam mendeteksi level ketinggian air menggunakan 3 metode, yaitu cara sentuh air langsung melalui kawat nikelin, pemanfaatan pelampung dengan encoder dan penggunaan sensor tekanan. Melalui penelitian ini, metode deteksi level ketinggian air dapat dijadikan acuan untuk mendapatkan data ketinggian air sungai yang selanjutnya dihubungkan melalui koneksi IoT (Qiu et al., 2012) atau internet sebagai rujukan untuk penelitian selanjutnya.

\section{METODE PENELITIAN}

Kontsruksi deteksi ketinggian air salah satunya dibangun menggunakan pipa paralon 3-inch dengan meletakkan pelampung di dalamnya. Pelampung berupa bola pingpong yang diisi air. Air yang diisikan sejumlah setengah dari volume total bola. Bola diletakkan di dalam peralon sebagai pengapung untuk menggerakkan encoder yang dihubunkgan dengan bola melalui tali. Ujung tali dipasangkan pelampung bola pingpong sebagai pemberat. Bola pingpong diisi air sepertiga bagian dari volume bola. Semakin tinggi air maka semakin tinggi pula pelampung. Pergerakan pelampung ke atas mengakibatkan encoder berputar dan perubahan dapat diteteksi.

Deteksi ketinggian juga menggunakan sensor tekanan. Pengoperasian sensor tekanan didasarkan pada deteksi yang timbul dari perbedaan tekanan. Sensitivitas sensor tergantung defleksi diafragma yang disebabkan oleh berat cairan yang dihasilkan tekanan hidrostatik, yang merupakan fungsi dari tinggi dan kepadatan kolom udara yang tertekan cairan. Peningkatan tekanan di bagian atas pipa berbanding terbalik dengan volume udara yang tertekan ketinggian kolom cairan.

Deteksi ketinggian selanjutnya adalah menggunakan metode resistansi dan kapasitansi dari elektroda yang digambarkan menggunakan kawat nikelin dalam bentuk pola menyerupai sisir dengan jarak setiap 10 mm. Bagian yang tidak dililit diberi lapisan licin efek daun talas, sehingga air tidak menempel di sela-sela elektroda. Semakin tinggi level air maka semakin banyak elektroda yang terkena air. Keadaan ini mengakibatkan semakin kecil resistansi dan nilai kapasitansinya pun berubah.

Langkah selanjutnya adalah pengujian akurasi hasil pembacaan sensor. Hasil pembacaan ketinggian air dari masing-masing sensor digunakan sebagai penentu model pembacaan air yang tepat di rentang tertentu. Klasisifikasi rentang pembacaan dibagi berdasarkan nilai akurasi dari masing masing sensor. Dalam hal ini akan dibagi menjadi dua level ketinggian untuk masing masing sensor.

Pembacaan menggunakan encoder akan memiliki tingkat akurasi dan presisi yang berbeda dibandingkan dengan sensor tekanan ataupun dengan pengukuran metode resistansi maupun dengan encoder. Pada rentang level tertensu setiap jenis sensor dapat saja menunjukkan ketinggian air yang berbeda. Pada level ketingggian tertentu, hasil pengukuran akan dipilih dari hasil pembacaan yang paling tepat. Sehingga akan didapatkan sensor manakah yang paling presisi dan paling akurat dari tiap tingkatan level ketinggian.

\section{HASIL DAN PEMBAHASAN}

Sistem telah berhasil dirancang dan beberapa bagian mulai diimplementasikan. Bagian yang sudah diimplementasikan yaitu metode sentuh air dan metode tidak sentuh air. Metode sentuh air menggunakan media kawat nikelin yang dililitkan ke dalam pipa ukuran diameter luar $48 \mathrm{~mm}$. Selanjutnya pipa tersebut dicelupkan ke air, sehigga kawat nikelin menyentuh air. Metode tidak sentuh aur menggunakan sensor tekanan yang dipasangkan pada pipa yang berdiameter sama, $48 \mathrm{~mm}$, pada atas pipa. Pipa dibuat agar tidak bocor dengan menutupnya dengan lem pipa. Metode lain adalah menggunakan metode pengukuran jarak air dengan bantuan encoder dan pelampung.

Percobaan pembacaan data ketinggian air menggunakan kawat nikelin menghasilkan nilai yang tidak linier. Saat level air rendah, perubahan nilai ADC semakin tinggi hingga batas nilai ketinggian $30 \mathrm{~cm}$. Selanjutnya, setelah ketinggian $30 \mathrm{~cm}$, nilai ADC mulai bergerak degan perubahan hampir linier. 


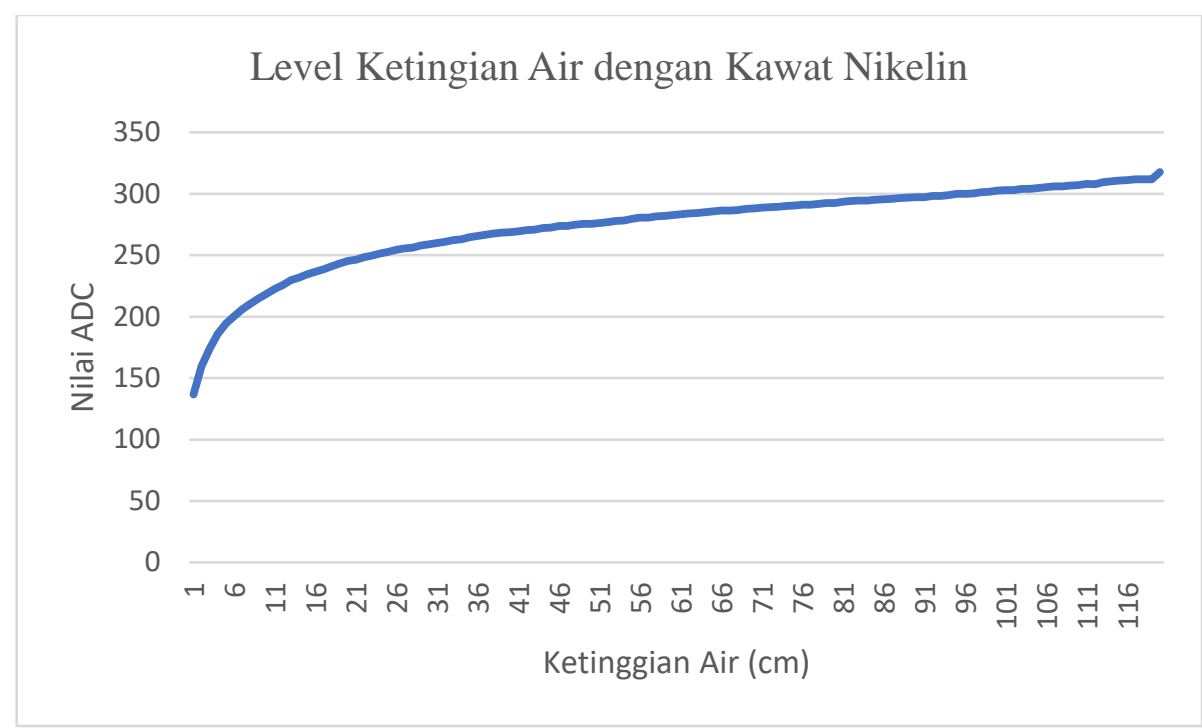

Gambar 1. Grafik Nilai ADC terhadap ketinggian air

Pembacaan ketinggian air menggunakan sensor tekanan adalah linier terhadap ketinggian air. Hanya saja perubahan tekanan sangat kecil, yaitu rata-rata $1 / 40 \mathrm{inHg} / \mathrm{cm}$. Hal tersebut membutuhkan sensor tekanan yang sangat akurat untuk dapat mendeteksi perubahan ketinggian air $1 \mathrm{~cm}$. Penggunaan sensor ini lebih tepat dipasang apabila perubahan ketinggian air cukup besar, lebih dari $10 \mathrm{~cm}$.

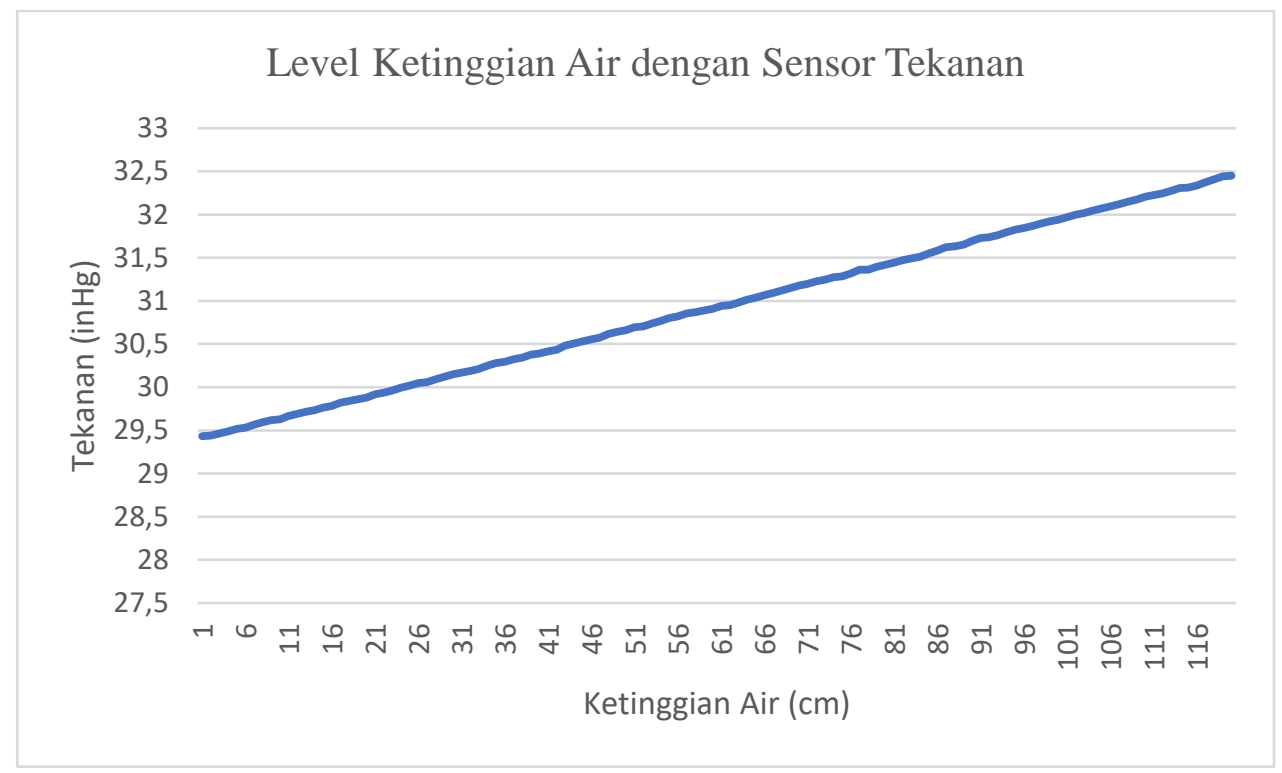

Gambar 2. Grafik tekanan terhadap ketinggian air

Percobaan menggunakan encoder, dengan memasang pelampung, didapatkan hasil yang linier. Hanya saja metode ini membutuhkan perawatan mekanik yang cukup rumit. Bandul dan tali riskan untuk berubah posisi dikarenakan friksi yang kecil antara tali dan encoder. Encoder yang digunakan pada penelitian ini berdiameter $4 \mathrm{~cm}$ dengan piranti encoder 400 pulsa tiap putaran. Perbandingan berat bandul terhadap pelampung adalah 3:1. Sebuah katrol dipasang untuk menaruh bandul di luar pipa. 


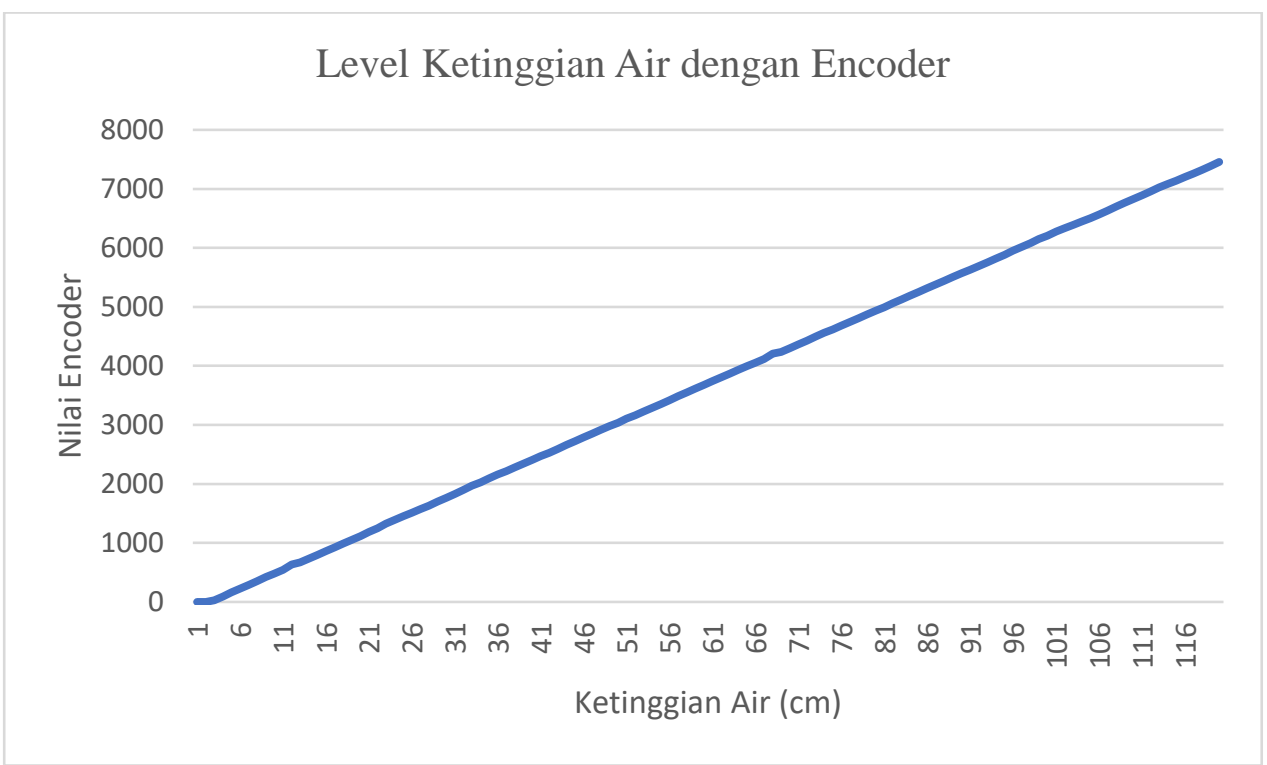

Gambar 3. Grafik Nilai encoder terhadap ketinggian air

\section{KESIMPULAN}

Berdasarkan data yang telah diperoleh dari beberapa metode deteksi ketinggian air maka metode tersebut masing-masing dapat diterapkan pada keadaan tertentu sesuai dengan estimasi tingkat perubahan ketinggian air. Untuk perubahan ketinggian air yang kurang dari $30 \mathrm{~cm}$, metode yang digunakan dapat berupa pemanfaatan encoder. Metode ini mampu mendeteksi 5 hingga 6 hitungan per kenaikan $1 \mathrm{~mm}$ ketinggian air, atau dengan kata lain dapat mendeteksi akurasi ketinggian $0,17 \mathrm{~mm} / \mathrm{step}$. Rerata kesalahan baca dari metode ini adalah $0,065 \mathrm{~mm} / \mathrm{step}$.

Pengukuran ketinggian air yang memiliki rentang $50 \mathrm{~cm}$ ke atas hingga dapat menggunakan metode pemanfaatan kawat nikelin, dimana perubahan nilai resistansi kawat sudah mulai linier sejak level air lebih dari 30 $\mathrm{cm}$. Nilai perubahan ADC adalah 2,93 mV/cm. Pada penelitian ini, ADC yang digunakan adalah 10 bit dengan Vref 5 Volt.

Pada perubahan level ketinggian $50 \mathrm{~cm}$ ke atas dapat menggunakan metode pemanfaatan sensor tekanan dapat digunakan, namun perubahan tekanan sebesar $0,002 \mathrm{inHg} / \mathrm{mm}(0,05 \mathrm{mmHg} / \mathrm{mm})$ membutuhkan sensor dengan akurasi tinggi.

Penggunaan sensor tekanan dapat dilakukan jika ingin mengetahui pertubahan tekanan tiap satuan $10 \mathrm{~mm}$, dimana nilai perubahan tekanan $0,5 \mathrm{mmHg} / \mathrm{cm}$. Dengan demikian, dapat menggunakan sensor tekanan yang mampu mendeteksi perubahan tekanan lebih dari atau sama dengan $0,5 \mathrm{mmHg}$.

\section{UCAPAN TERIMA KASIH}

Penulis ucapkan Terima kasih yang sebesar besarnya kepada Lembaga Penelitian dan Pengabdian Masyarakat universitas Muhammadiyah Purwokerto yang telah mendanai penuh penelitian ini.

\section{DAFTAR PUSTAKA}

Akhiruddin, A. (2018). Rancang Bangun Alat Pendeteksi Ketinggian Air Sungai Sebagai Peringatan Dini Banjir Berbasis Arduino Nano. JET (Journal of Electrical Technology), 3(3), 174-179.

Ameen, O. F., Younus, M. H., Aziz, M. S., Azmi, A. I., Ibrahim, R. K. R., \& Ghoshal, S. K. (2016). Graphene diaphragm integrated FBG sensors for simultaneous measurement of water level and temperature. Sensors and Actuators A: Physical, 252, 225-232.

Arief, U. M. (2011). Pengujian Sensor Ultrasonik PING untuk Pengukuran Level Ketinggian dan Volume Air. 09(02).

BBC News Indonesia. (n.d.). BMKG prediksi cuaca ekstrem "akan terjadi hingga Oktober", "curah hujan lebih tinggi", dan masyarakat "harus waspada" - BBC News Indonesia. Retrieved October 26, 2020, from https://www.bbc.com/indonesia/indonesia-54230888

Chetpattananondh, K., Tapoanoi, T., Phukpattaranont, P., \& Jindapetch, N. (2014). A self-calibration water level measurement using an interdigital capacitive sensor. Sensors and Actuators A: Physical, 209, 175-182.

Qiu, T., Ding, Y., Xia, F., \& Ma, H. (2012). A search strategy of level-based flooding for the internet of things. In 
Sensors (Switzerland) (Vol. 12, Issue 8). https://doi.org/10.3390/s120810163

Raji, W. O., \& Adedoyin, D. O. (2019). Dam Safety Assessment Using 2D Electrical Resistivity Geophysical Survey. Journal of King Saud University - Science. https://doi.org/10.1016/j.jksus.2019.10.016

Satria, D., Yana, S., Munadi, R., \& Syahreza, S. (2017). Sistem Peringatan Dini Banjir Secara Real-Time Berbasis Web Menggunakan Arduino dan Ethernet. 1(1), 1-6. 